\title{
ANALYSIS OF AIR POLLUTANT EMISSIONS IN A WASTEWATER TREATMENT PLANT USING DISPERSION MODELS
}

\author{
LORENZO FILENI ${ }^{1}$, GIORGIO MATTEUCCI ${ }^{1}$, GIORGIO PASSERINI ${ }^{1}$ \& UMBERTO RIZZA ${ }^{2}$ \\ ${ }^{1}$ Department of Industrial Engineering and Mathematical Sciences, Polytechnic University of Marche, Italy \\ ${ }^{2}$ Institute of Atmospheric Sciences and Climate, National Research Council of Italy, Italy
}

\begin{abstract}
The dispersion of air pollutants such as Ammonia $\left(\mathrm{NH}_{3}\right)$ and Hydrogen Sulphide $\left(\mathrm{H}_{2} \mathrm{~S}\right)$ emitted by a municipal wastewater treatment plant (WWTP) was studied for a period of over one year. The main intent was to support the environmental impact assessment focusing on the diffusion of annoying odours over surrounding areas during the regular activity of the sewage treatment facility. The adopted methodology consists in comparing, in three test cases, the performance of the Gaussian plume model AERMOD, an American Meteorological Society and U.S. Environmental Protection Agency Regulatory Model, against the performance of the 3-D Lagrangian model AUSTAL2000, a German Dispersion Model developed according to the Technical Instructions on Air Quality Control. Both models were run over a domain of about $30 \mathrm{~km}^{2}$ made of hilly zones and located in the centre-eastern Italy. Ten sources of airborne pollutants, located along the sludge treatment line and considered as area sources, were taken into account. The diffuse emissions associated with odour production within WWTP were estimated considering the pollutant emission factors suggested by the American Environmental Protection Agency (EPA). The test cases included different emission scenarios deriving from three different operative plant configurations set in order to investigate the most impacting one. The results show a good agreement between the two model outputs since the annual average for $\mathrm{NH}_{3}$ and $\mathrm{H}_{2} \mathrm{~S}$ are almost equivalent. These concentrations are below the legal limits while the highest values, measured at closest receptors, are beneath the odour perceptibility thresholds. Some noteworthy differences concern the AERMOD distribution maps that show a sort of pollutant stagnation over complex topography areas, especially in valleys, and a farer allocation of the highest pollutants levels from the source, while the AUSTAL2000 model is more biased to distribute the highest values closer to the sources.
\end{abstract}

Keywords: AERMOD, AUSTAL2000, hydrogen sulphide, ammonia, odour emissions, wastewater treatment plant, sludge unity treatment.

\section{INTRODUCTION}

Dispersion models simulate the fate of gases and airborne particles and help to predict the concentrations of pollutants in the atmosphere. They are important tools in air quality management and planning given that they are cost-effective and time-effective alternatives to field measurements [1]. These models are often used over wide domains to predict or to evaluate the concentration of primary or secondary airborne pollutants. In this study the authors focused on a rather small domain where a wastewater treatment plant (WWTP) represented the only source of Ammonia $\mathrm{NH}_{3}$ and Hydrogen Sulphide $\mathrm{H}_{2} \mathrm{~S}$ emissions.

The waste water treatment facilities play a key role in the environmental protection being involved in reception, storage, treatment, and disposal of an often variegated stream of sewage from municipalities and industries that may include petrochemicals, science-based industries (i.e. semiconductors, photo-electronics and electronic products), food industries (livestock, slaughterhouses, sugar factories etc.) as well as multiple manufacturing processes (i.e. pharmaceuticals, biological technology and paint manufacturing). Thus, emissions of malodorous gaseous compounds and of airborne pollutants from wastewater collection and 
treatment facilities are a rising maintenance costs and ecological problems. Among the most relevant gaseous pollutants, volatile organic compounds (VOCs) represent a key issue. VOCs were monitored in the different sections of a WWTP by Wu et al. [2] and by Cheng et al. [3]. They also discerned several types of VOCs in function of diverse industrial sectors, while Devai et al. analysed the quantity and composition of malodorous sulphur gases emitted from various stages of waste water treatment process [4]. Easter et al. proposed a solution, using biotechnology, to control odour annoyance caused by hydrogen sulphide emission (H2S) and VOCs [5]. The present study shows the results of a tentative application of two dispersion models, AERMOD and AUSTAL2000, to analyse the concentrations due to the dispersion of $\mathrm{NH} 3$ and $\mathrm{H} 2 \mathrm{~S}$ emitted by the sludge treatment units of a publicly owned treatment plant, to compare the amount of air pollutants and odour emissions among three different operative plant configurations and to identify the most accurate model to support an environmental impact assessment. The simulations were carried out over about one-year time span in order to consider seasonal variation of the WWTP activities and therefore the relative gaseous emissions. Daelman et al. performed a similar study [6] also adopting an on-line measurement campaign of methane and nitrous oxide during 16 months. The use of dispersion models in this field was already tackled by Melcer et al. [7] in order to analyse the VOC's dispersion in a WWTP and by Schulthess et al. who investigated the release of N2O from a denitrifying activated sludge system [8]. More recently, other mathematical modelling developments were carried out by Shahabadi et al. in 2010 to evaluate the GHG emissions (mainly CO2) in a WWTP [9] while Corominas et al. in 2012 presented an application of process-based dynamic models to better calculate the GHG emissions (mainly $\mathrm{CO} 2$ and $\mathrm{CH} 4$ ) and the emission of $\mathrm{NO} 2$ [10]. The site was selected given its proximity to a relevant industrial area that surrounds the WWTP itself and where hundreds of workers are employed, whereas the pollutants have been selected because of their toxicity and odorous impact of ambient air. The authors considered this study necessary as a further application and contribution to the understanding of dispersion modelling. In fact, it shows the impact of a WWTP in terms of odour emissions and dispersion all over the domain to help identifying the most suitable model to support the policy-makers in environmental management activities, depending on the domain and on the characteristics of emission sources.

\section{METHODOLOGY}

The present study was performed over a hilly zone in the centre-east of Italy, a $30 \mathrm{~km}^{2}$ domain area centred over the WWTP of Camerano (Ancona province) the plant being located at $20 \mathrm{~m}$ above the see level. The authors compared, in three different test cases, the performance of the Gaussian plume model AERMOD, an American Meteorological Society and U.S. Environmental Protection Agency Regulatory Model, against the 3-D Lagrangian model AUSTAL2000, a Dispersion Model developed according to the German Technical Instructions on Air Quality Control.. The two main steps consisted in quantifying the emissions of $\mathrm{NH}_{3}$ and $\mathrm{H}_{2} \mathrm{~S}$ from sludge treatment units according to three different scenarios and in estimating the local concentrations of both gases by means of intensity maps.

\subsection{Features of employed models}

AERMOD is a steady-state plume dispersion model designed for short-range simulations (up to 50 kilometres) in meteorological conditions that are assumed to be constant during the modelling period of $1 \mathrm{hr}$ and horizontally homogenous. AERMOD is applicable over flat and complex terrains, within rural and urban areas affected by multiple surface/elevated emission sources (including, point, area and volume sources). This model does not differentiate 
between different pollution types, but algorithms for dry and wet deposition are incorporated. In stable boundary layer conditons, with stable and neutral stratification (Monin-Obukhov length $>0$ ), it assumes a Gaussian concentration distribution both in vertical and in horizontal crosswind. In convective boundary layer conditions, within convective and neutral conditions, (Monin-Obukhov length $<0$ ) the vertical distribution is described with a biGaussian probability density function.

In complex-topography zones AERMOD handles the terrain in a consistent and continuous way by considering the dividing streamline concept in stably stratified conditions [11]. According to this concept, AERMOD is able to simulate a plume flowing over the hill as well as a plume flowing around it. This means that the model can simulate a plume either impacting and/or following the terrain. In 'urban mode', AERMOD accounts for the dispersive nature of the urban thermal effects that form during night-time in the boundary layer when stable rural air flows over a warmer urban surface. AERMOD scales this effect by population size.

AERMOD employs several surface meteorological parameters such as wind speed, wind direction, temperature. Moreover, it requires friction velocity, vertical potential temperature gradient, height of the convectively boundary layer, and surface roughness length (z0). Surface characteristics (surface roughness, Bowen ratio, and albedo) are also needed in order to construct similarity profiles of the relevant PBL parameters. The modelling chain consists of a main module (AERMOD) and two pre-processors (AERMET and AERMAP). The major purpose of AERMET is to calculate boundary layer parameters employed by the meteorological interface, internal to AERMOD, to generate vertical profiles of the meteorological variables.

AUSTAL2000 is a steady-state dispersion model designed for long-term sources and continuous buoyant plumes. It solves the concentration field using a non-steady Lagrangian approach. Like AERMOD, it is capable of addressing multiple point, area, volume, and line sources. The pollutant sources are simulated through the release of particles that are carried by the wind and scattered by turbulence phenomena. Wind direction and horizontal wind speed are described by a vector field whereas the vector of the turbulent velocity is randomly varied for every particle by using a Markov process. The model includes dry deposition algorithms and considers the conversion of nitric oxide (NO) to nitrogen dioxide $\left(\mathrm{NO}_{2}\right)$. It is also able to make predictions about the frequency of odour nuisance the concentrations being determined by counting the particles in a given volume.

AUSTAL2000 can also take into account the complex orography of the domain and it contains its own algorithm to assess the effects of building downwash. The modelling chain includes a meteorological processor called TALDIA that allows the evaluation of the meteorological field on the whole domain. To run this processor, the model necessitates less meteorological input than AERMOD: z0, wind measurement height, wind direction, wind speed, and the stability classes according to Klug-Manier (German standard atmospheric stability classification similar to the well-known Pasquill stability classification). All of these meteorological data come from ground-based measurements and no information from upper air soundings is utilized [1].

\subsection{Wastewater treatment plant configurations}

The emissions associated with odour production from WWTP were estimated considering the emission factors suggested by the American Environmental Protection Agency (EPA) [12]. The classification of process steps has been realized in order to take into account 
olfactory impact related to the individual phases. They were merged phases technologically different as long as united by similar odour emissions (see Table 1).

The following emission sources have been identified in the sludge line of the WWTP: new post-thickener (D1), new centrifuge (D2), new pre-thickener (D3), sludge uplifting from primary sedimentation (D4), active sludge uplifting (D5), primary sludge uplifting from equalization pool (D6), re-circulation sludge uplifting (D7), thickener (D8), current centrifuges room (D9), drying beds (D10). Fig. 1 shows the facility plan with the position of each unit.

The three simulation scenarios correspond to three different processing configurations and may be recapped as:

1. Uplifting and over-flow units, primary and secondary sedimentation, equalizer, prethickening, current centrifuges room, drying beds;

2. Uplifting and overflow units, primary and secondary sedimentation, pre-thickening, anaerobic digestion, gas holder, torch, thickening, post-thickening, current centrifuges room and drying beds;

3. Uplifting and overflow units, primary and secondary sedimentation, pre-thickening, anaerobic digestion, gas holder, torch, post-thickening, new centrifuges room and drying beds.

As already mentioned, following the advice of Italian Environmental Authorities and the literature [5], the authors selected $\mathrm{NH}_{3}$ and $\mathrm{H}_{2} \mathrm{~S}$ as odour 'tracers' thanks to their medical and biological effects on human beings due to exposition even at very low concentrations. In fact, the human perceptible thresholds are $0.00041 \mathrm{ppm}\left(0.6 \mu \mathrm{g} / \mathrm{m}^{3}\right)$ and $0.037 \mathrm{ppm}$ respectively for $\mathrm{H}_{2} \mathrm{~S}$ and $\mathrm{NH}_{3}$. Due to the absence of limit reference values for these gases, the simulations output have been compared with the perceptible thresholds itself for the $\mathrm{H}_{2} \mathrm{~S}$ and with $25 \mu \mathrm{g} / \mathrm{m}^{3}$ for the Ammonia (this value results from several air quality control campaigns carried out by local environmental agencies).

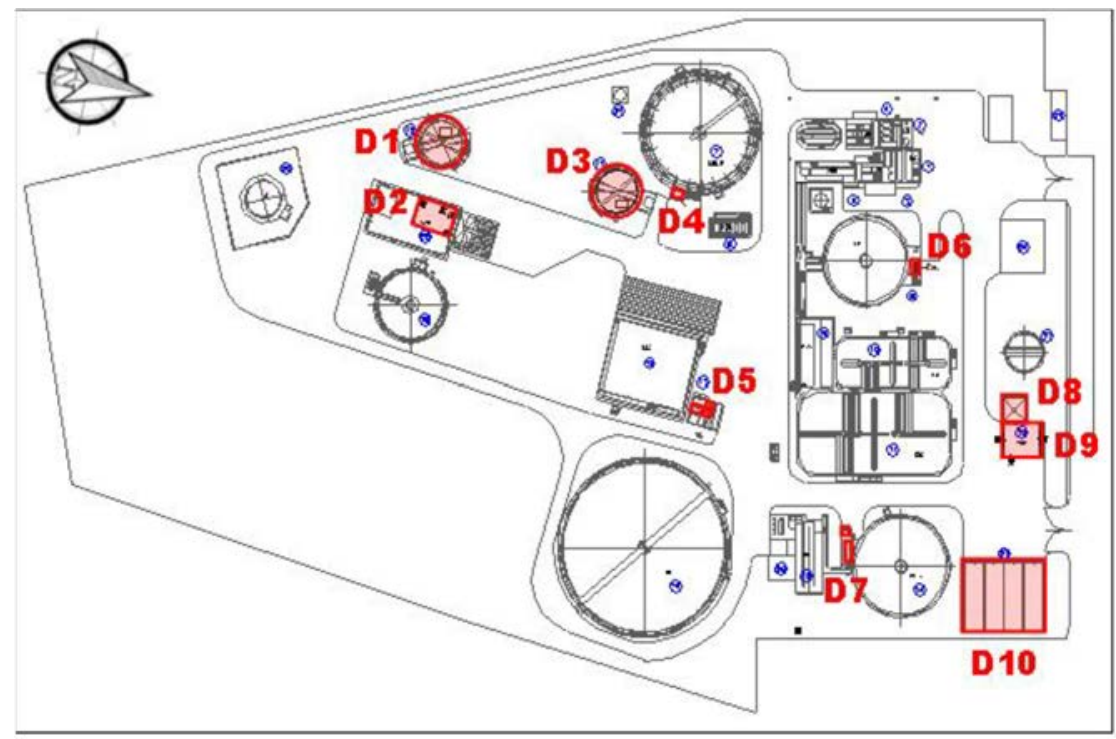

Figure 1: Plan of sewage treatment facility. 
Table 1: Main activities in the WWTP and related emitted pollutants.

\begin{tabular}{|c|c|c|}
\hline Activity & Emission sources & Odorous pollutants \\
\hline \multirow{8}{*}{$\begin{array}{l}\text { Urban sewage } \\
\text { treatment units }\end{array}$} & $\begin{array}{l}\text { Sewerage uplifting units and/or } \\
\text { draining from tanker trucks }\end{array}$ & \multirow{12}{*}{$\begin{array}{c}\mathrm{H}_{2} \mathrm{~S} \\
\mathrm{NH}_{3} \\
\text { Sulphurous organic } \\
\text { compounds } \\
\text { Reduced sulphurous } \\
\text { organic compounds } \\
\text { Amines } \\
\text { Indole and Skatole } \\
\text { organics } \\
\text { Fatty volatile acids } \\
\text { Other organic } \\
\text { compounds }\end{array}$} \\
\hline & Pre-treatment & \\
\hline & Primary sedimentation & \\
\hline & Biologic oxidation & \\
\hline & Nitrification & \\
\hline & Denitrification & \\
\hline & Secondary sedimentation & \\
\hline & Final treatment & \\
\hline \multirow{4}{*}{$\begin{array}{l}\text { Sludge treatment and } \\
\text { energy production units }\end{array}$} & Thickening & \\
\hline & Mechanic treatments & \\
\hline & Thermal dewatering & \\
\hline & $\begin{array}{l}\text { Anaerobic digestion } \\
\text { Biogas production }\end{array}$ & \\
\hline
\end{tabular}

\subsection{Estimation of emissions}

The emissions arising from the thickener and uplifting units (primary sludge, activated sludge, sludge recirculation) were quantified according to the emission factors proposed by EPA [12]. Moreover, the following additional features have been considered in order to properly estimate the emissions: pool areas, tank volumes, flow rates, daily working hours, wastewater temperatures, pollutant concentrations in the wastewater at the plant entrance and the local wind speeds. The volatilization rate can be determined using the theory of mass transfer. The individual mass transfer coefficients of the gaseous and liquid phases $(\mathrm{kg}$ and $\mathrm{kl})$, are used to estimate the global transfer coefficients for each compound organic $\left(K, K_{D}\right)$. To estimate the rate of emissions (hereafter $N$ ) the first step is to calculate the mass transfer coefficients $\left(K_{l}\right.$ and $\left.K_{g}\right)$ and then, the global mass transfer coefficient $K$ by which is possible to calculate emissions. Fig. 2 shows the flow diagram proposed by EPA [12] for the estimation of emissions, depending on the procedure such as treatment, storage, collection, etc. Henry's law (HLC) is applied to measure the diffusion of organic matter in the air. The related values in conditions of high volatility, medium volatility and low volatility are:

- High: HCL $>10^{-3}$ atm- $\mathrm{m}^{3} / \mathrm{gmol}$

- Medium: $10^{-3}$ atm- $\mathrm{m}^{3} / \mathrm{gmol}<\mathrm{HLC}<10^{-5}$ atm- $\mathrm{m}^{3} / \mathrm{gmol}$

- Low: HLC $<10^{-5}$ atm- $\mathrm{m}^{3} /$ gmol

In Fig. $2 K_{l}$ is individual liquid-phase mass-transfer coefficient $[\mathrm{m} / \mathrm{s}], K_{g}$ is individual gasphase mass-transfer coefficient $[\mathrm{m} / \mathrm{s}], K_{\text {oil }}$ is overall mass-transfer coefficient in the oil phase $[\mathrm{m} / \mathrm{s}], \mathrm{K}_{\mathrm{D}}$ is volatilization, $\mathrm{K}$ is overall mass-transfer coefficient $[\mathrm{m} / \mathrm{s}], N$ is emission $[\mathrm{g} / \mathrm{s}], A$ is pool surface, $R$ is universal gas constant, $H$ is Henry's constant for gases, $T$ is water temperature, $Q$ is incoming flow rate in the pool, $C_{0}$ is incoming pollutant concentration. The formulas to calculate the parameters are:

$$
k_{l}=\left(2.78 * 10^{-6}\right)\left(\frac{D_{w}}{D_{\text {ether }}}\right)^{2 / 3},
$$




$$
\begin{gathered}
k_{g}=\left(4.82 * 10^{-3}\right)\left(U_{10}\right)^{0.78}\left(S_{c g}\right)^{-0.67}\left(d_{e}\right)^{-0.11}, \\
K=\frac{k_{l} K_{e q} k_{g}}{K_{e q} k_{g}}+k_{l},
\end{gathered}
$$

where the gas equilibrium constant is determined as:

$$
K_{e q}=H /(R T),
$$

finally, the emission rate is determined as:

$$
N=k C_{l} A,
$$

with the parameter $\mathrm{C}_{1}$ determined by:

$$
C_{l}=Q C_{0}(K A+Q) .
$$

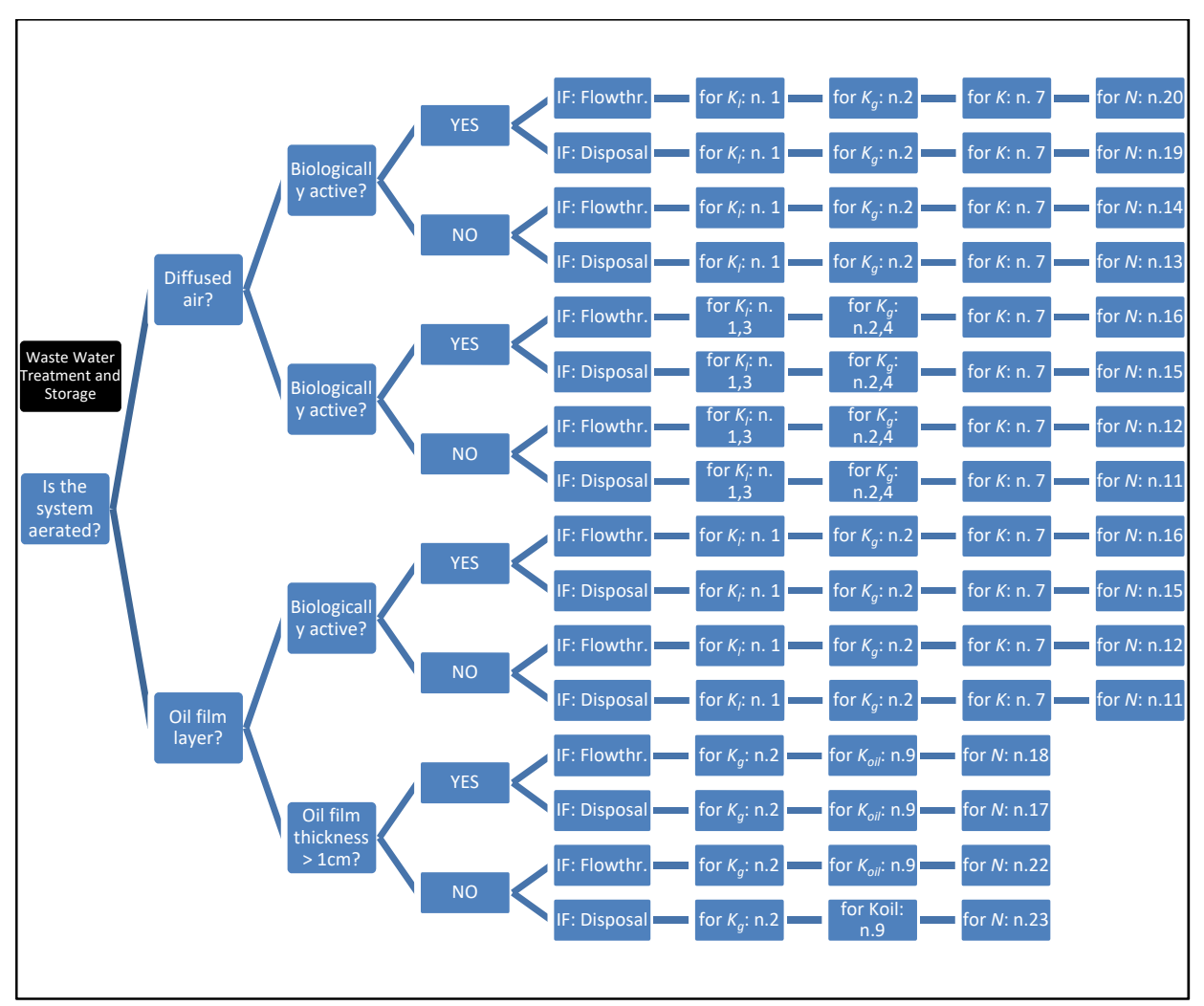

Figure 2: EPA formula's flowchart. 
Table 2: Emission factors from WWTP units calculated for both gases.

\begin{tabular}{|c|c|c|}
\hline Source & $\mathrm{NH}_{3}(\mathbf{g} / \mathbf{s})$ & $\mathbf{H}_{2} \mathrm{~S}(\mathbf{g} / \mathbf{s})$ \\
\hline D1: new sludge post-thickener & $3.17 \mathrm{E}-06$ & $9.59 \mathrm{E}-09$ \\
\hline D3: new sludge pre-thickener & $1.37 \mathrm{E}-05$ & $4.13 \mathrm{E}-08$ \\
\hline D4: sludge uplifting at sedimentation & $1.87 \mathrm{E}-05$ & $5.46 \mathrm{E}-08$ \\
\hline D5: activated sludge uplifting & $9.04 \mathrm{E}-03$ & $9.92 \mathrm{E}-06$ \\
\hline D6: sludge uplifting from equalizer pool & $2.18 \mathrm{E}-03$ & $1.2 \mathrm{E}-05$ \\
\hline D7: re-circulation sludge uplifting & $7.41 \mathrm{E}-03$ & $3.76 \mathrm{E}-05$ \\
\hline D8: thickener & $5.94 \mathrm{E}-06$ & $1.78 \mathrm{E}-08$ \\
\hline \multicolumn{2}{|c}{} \\
\hline
\end{tabular}

Table 3: Emission factors from dewatering units calculated for both gases.

\begin{tabular}{|c|c|c|}
\hline \multicolumn{1}{|c|}{ Source } & $\mathrm{NH}_{3} \mathbf{( g / s )}$ & $\mathbf{H}_{2} \mathbf{S} \mathbf{( g / s )}$ \\
\hline D2: new centrifuge room & $2.23 \mathrm{E}-01$ & $2.74 \mathrm{E}-03$ \\
\hline D9: present centrifuge room & $2.61 \mathrm{E}-01$ & $3.21 \mathrm{E}-03$ \\
\hline D10: drying beds & $1.93 \mathrm{E}-03$ & $2.38 \mathrm{E}-05$ \\
\hline
\end{tabular}

Table 2 shows emission rates for each WWTP unit and for both gases evaluated according to such formulas.

The diffuse emissions deriving from the dehydration systems (centrifuge and drying beds) were quantified assuming that all the pollutants detected in the sludge are released into the atmosphere. In this way the result is definitely overestimated so that impact assessment is cautionary. During centrifuge operations, the dehydrated sludge is accumulated within covered containers and after a few days sent to external disposal. At this point, it was deemed appropriate not to consider the mud in the caissons among the emission sources to avoid further overestimates. In fact, the diffuse emissions resulting from the centrifuge have been largely overestimated, the contribution of drying beds was also considered, although in reality are used only in emergency conditions. Finally, the mud in the caissons is stored after stabilization covered and for short periods only.

Such sources were simulated as area sources. The content of dry matter in the sludge, the inflow rate, the daily working hours and the concentration of pollutants in the wastewater at WWTP entrance were considered as input data. Table 3 shows the emission rates for each dewatering unit and for both gases evaluated according to the above formulas.

\section{RESULTS AND DISCUSSIONS}

Three simulations were performed related to three operative configurations: the current situation, start of anaerobic digester using the centrifuge at the current position, start of anaerobic digester and centrifuge relocated in a new room. For all simulations, similar results were obtained through both models. All values for hydrogen sulphide $\left(\mathrm{H}_{2} \mathrm{~S}\right)$ and ammonia $\left(\mathrm{NH}_{3}\right)$ result under the law limits and the highest values measured in the receptor R2 (located in one of three houses surrounding the treatment plant) are below the threshold of perceptibility values. 

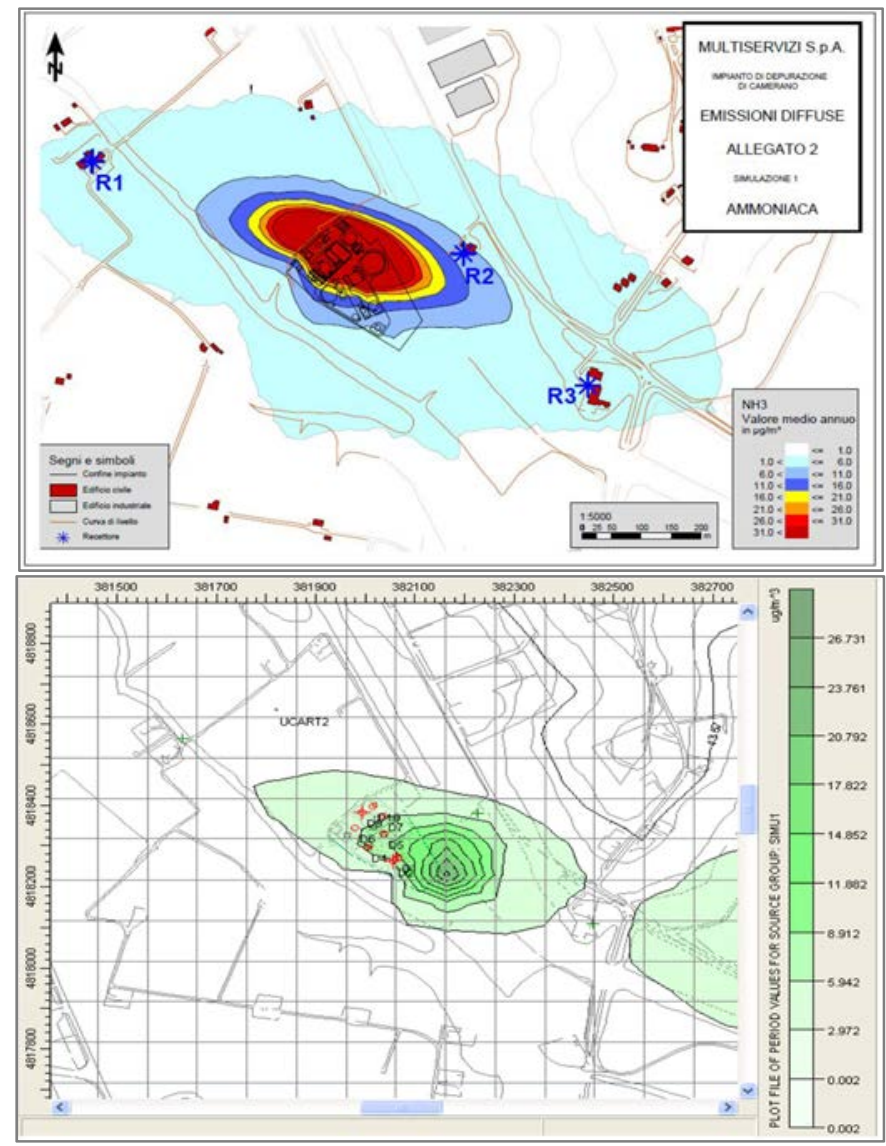

Figure 3: Output maps (AUSTAL2000 above and AERMOD below) of 1st simulation for ammonia gas dispersion.

The simulations for the first WWTP configuration show comparable ammonia dispersions as evaluated by the two programs. The closest receptor (receptor R2) shows a concentration of $7.42 \mu \mathrm{g} / \mathrm{m}^{3}$ and $4.67 \mu \mathrm{g} / \mathrm{m}^{3}$ calculated by AERMOD (Fig. 3). Such values are under the olfactory perception threshold established in the environmental impact assessment.

The results of the second simulation are almost identical to the first one as the only difference between these two simulations is the presence of the source D1 (new postthickener). The contribution of this source, in terms of ammonia emissions and hydrogen sulphide emissions is minor e.g. $10^{-6} \mathrm{~g} / \mathrm{s}$ against $10^{-3} \mathrm{~g} / \mathrm{s}$ order for ammonia (Fig. 4).

The ammonia concentrations, in the third simulation of AUSTAL2000 are lower in northeast and north-west areas. They are slightly higher in south-easterly areas. The value evaluated by AUSTAL2000 in receptor R2 is $3.67 \mu \mathrm{g} / \mathrm{m}^{3}$ (Fig. 5).

Concerning the $\mathrm{H}_{2} \mathrm{~S}$ concentrations, both programs estimated values rather similar as well. The highest recorded values were in the receptor R2 with $0.14 \mu \mathrm{g} / \mathrm{m}^{3}$ and $0.1 \mu \mathrm{g} / \mathrm{m}^{3}$ for AUSTAL2000 and AERMOD respectively. The highest values calculated by AERMOD are always lower than the olfactory threshold of $0.6 \mu \mathrm{g} / \mathrm{m}^{3}$. On the other hand, the values obtained 
from AUSTAL2000 close to the sources, are slightly higher than the olfactory threshold (Fig. 6).

The analysis of hydrogen sulphide in the second simulation shows, also for this gas, an irrelevant impact of the new post-thickener when compared with the first configuration of the sludge treatment units (Fig. 7).

In the third scenario, hydrogen sulphide concentrations decrease compared with the simulation 1 in the NE and NW areas while they grow slightly towards SE. The values remain below the olfactory threshold $\left(0.6 \mu \mathrm{g} / \mathrm{m}^{3}\right)$ even within most of the WWTP plant. The maximum value, computed by the AUSTAL2000 model, is still registered at the receptor R2, where the concentration is $0.07 \mu \mathrm{g} / \mathrm{m}^{3}$. The AERMOD outputs are slightly higher but below the threshold even inside the plant area, while at the receptor R2 a value less than $0.1 \mu \mathrm{g} / \mathrm{m}^{3}$ is calculated (Fig. 8).

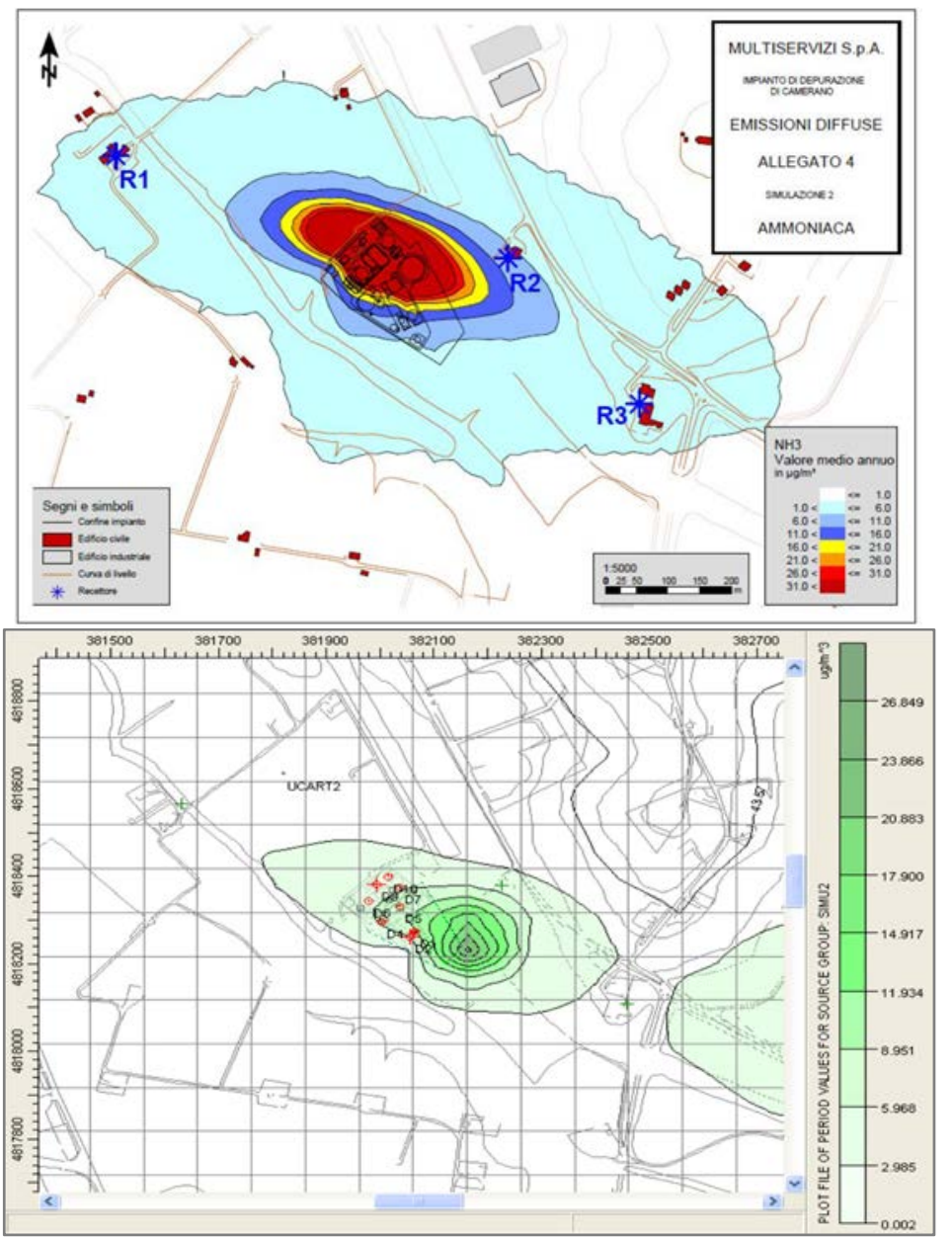

Figure 4: Output maps (AUSTAL2000 left and AERMOD right) of 2nd simulation for ammonia gas dispersion. 

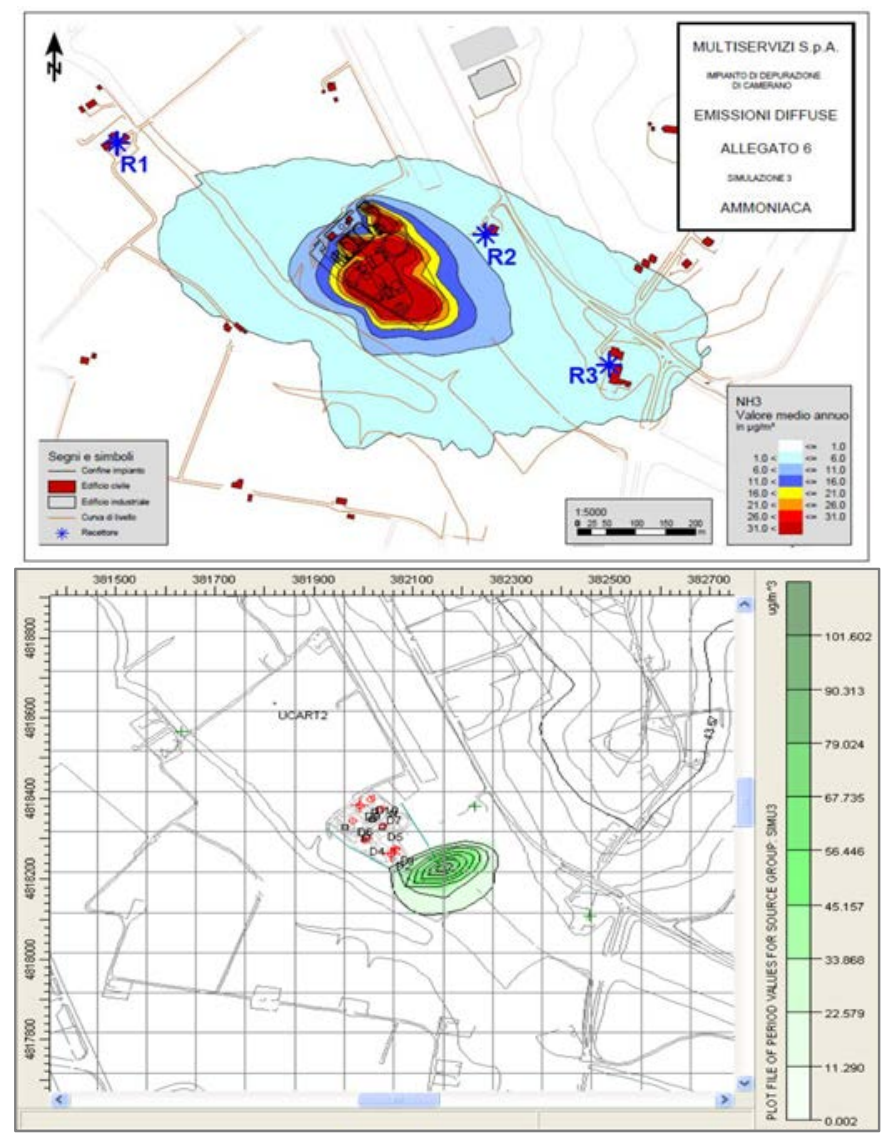

Figure 5: Output maps (AUSTAL2000 above and AERMOD below) of 3rd simulation for ammonia gas dispersion.
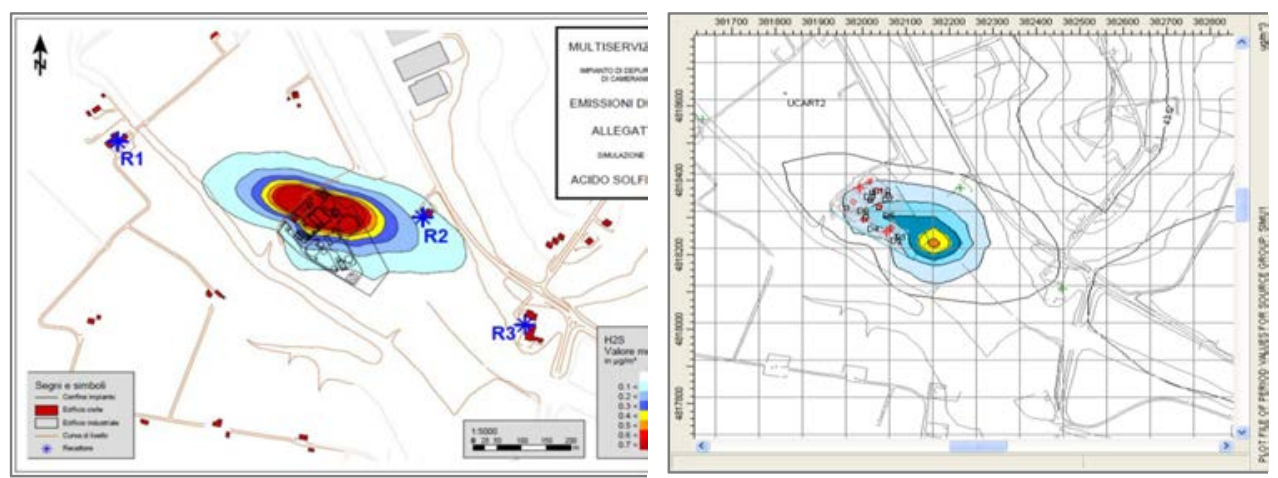

Figure 6: Output maps (AUSTAL2000 left and AERMOD right) of 1st simulation for hydrogen sulphide gas dispersion. 

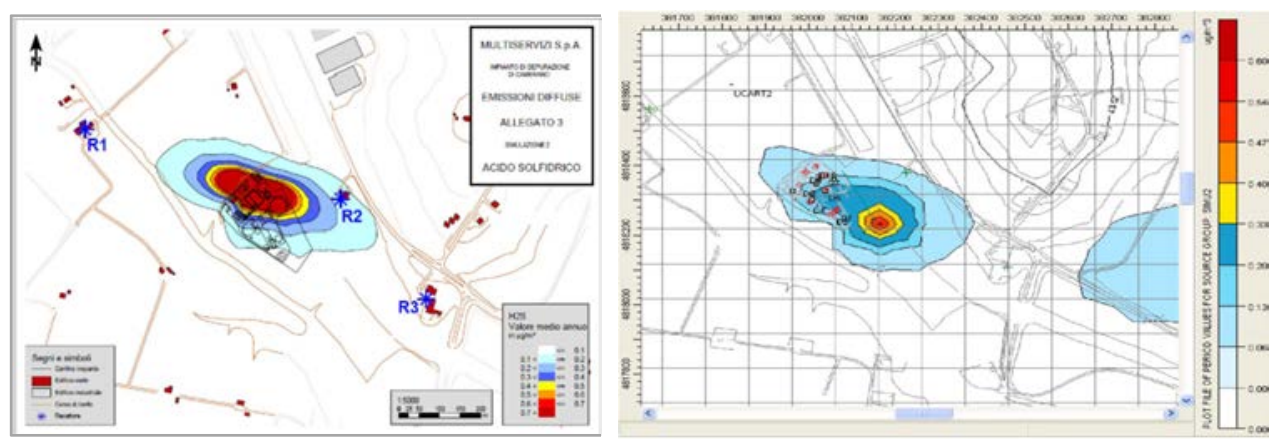

Figure 7: Output maps (AUSTAL2000 left and AERMOD right) of 2nd simulation for hydrogen sulphide gas dispersion.
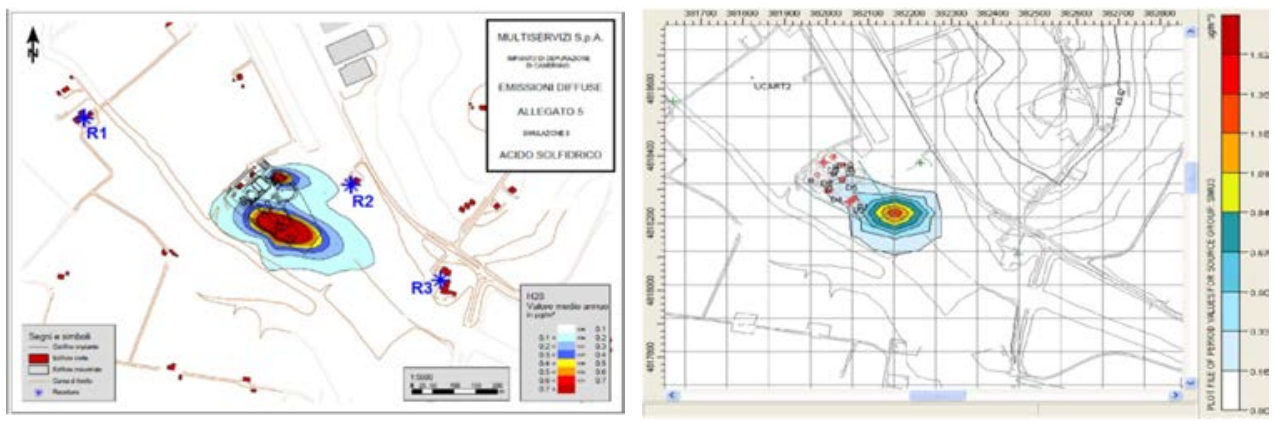

Figure 8: Output maps (AUSTAL2000 left and AERMOD right) of 3rd simulation for hydrogen sulphide gas dispersion.

\section{CONCLUSIONS}

Three simulations were performed in order to study the diffuse emissions from the sludge line of a WWTP located in the town of Camerano, province of Ancona (eastern side of Italy). The related concentrations have been evaluated by means of AUSTAL2000 and AERMOD. Each simulation was related to a specific scenario: the current configuration, start of anaerobic digestion using the centrifuge at the current position, start of anaerobic digestion and relocation of centrifuge in a new building.

The AERMOD output exhibited a sort of pollutant stagnation in the orographic depressions of areas with complex orography. This effect could be smoothed by elevating the grid receptors up to $10 \mathrm{~m}$. By comparing the two distributions, is noteworthy that the maximum values calculated by AERMOD, are more distant from the source downwind (toward the wind direction). These phenomena are probably due to the Gaussian nature of model.

The AERMET processing can be considered more accurate due to the amount of meteorological parameters required while the Gaussian approach might be considered a little bit less realistic than the Lagrangian one.

In general, AERMOD might be judged more suitable than AUSTAL2000 in diffusive studies over complex terrains and/or urban areas. The computational burden (namely the time required for simulations) is noteworthy. The algorithm of AUSTAL2000, took up to 10 hours 
to perform the simulations with a spike in computational time in case of complex orography while AERMOD spent less than 1 hour for the same simulations. On the other hand, the Lagrangian model AUSTAL2000 can be considered more suitable at least in three cases: whenever the additional meteorological parameters required by AERMOD are unavailable; whenever it is necessary to analyse the concentration field in a whole domain rather than in receptors only; whenever it is necessary to evaluate concentrations at different elevations over the ground.

\section{REFERENCES}

[1] Langner, C. \& Klemm, O., A comparison of model performance between AERMOD and AUSTAL2000. Journal of the Air \& Waste Management Association, 61(6), pp. 640-646, 2011. DOI: 10.3155/1047-3289.61.6.640.

[2] Wu, B.Z., Feng, T.Z., Sree, U., Chiu, K.H. \& Lo, J.G., Sampling and analysis of volatile organics emitted from wastewater treatment plant and drain system of an industrial science park. Analytica Chimca Acta, 576(1), pp. 100-111, 2006.

[3] Cheng, W.H., Hsu, S.K. \& Chou, M.S., Volatile organic compound emissions from wastewater treatment plants in Taiwan: Legal regulations and costs of control. Journal of Environmental Management, 88(4), pp. 1485-1494, 2008.

[4] Devai, I. \& DeLaune, R.D., Emission of reduced malodorous sulfur gases from wastewater treatment plants. Water Environment Research, 71(2), pp. 203-208, 1999.

[5] Easter, C., Quigley, C., Burrowes, P., Witherspoon, J. \& Apgar, D., Odor and air emissions control using biotechnology for both collection and wastewater treatment systems. Chemical Engineering Journal, 113(2)-(3), pp. 93-104, 2005.

[6] Daelman, M.R.J., van Voorthuizen, E.M., van Dongen, L.G.J.M., Volcken, E.I.P. \& van Loosdrecht, M.C.M., Methane and nitrous oxide emissions from municipal wastewater treatment - results from a long-term study. Water Science and Technology, 67(10), 2013.

[7] Melcer, H., Bell, J.P., Thompson D.J., Yendt C.M., Kemp J. \& Steel P., Modeling volatile organic contaminants' fate in wastewater treatment plants. Journal of Environmental Engineer, 120(3), 1994.

[8] Schulthess, R.V. \& Gujer, W., Release of nitrous oxide (N2O) from denitrifying activated sludge: Verification and application of a mathematical model. Water Research, 30(3), 1996.

[9] Shahabadi, B.M., Yerushalmi, L. \& Haghighat, F., Estimation of greenhouse gas generation in wastewater treatment plants - Model development and application. Chemosphere, 78(9), 2010.

[10] Corominas, L., Flores-Alsina, X., Snip, L. \& Vanrolleghem, P.A., Comparison of different modeling approaches to better evaluate greenhouse gas emissions from whole wastewater treatment plant. Biotechnology and Bioengineering, 109(11), 2012.

[11] Snyder, W.H. et al., The structure of the strongly stratified flow over hills: Dividing streamline concept. Journal of Fluid Mechanic, 152, pp. 249-288, 1985.

[12] US-EPA, AP42, cap. 4.3. Waste water collection, treatment and storage. 